\title{
Sylwia Pangsy-Kania
}

University of Gdańsk

e-mail: sylwia.pangsy-kania@ug.edu.pl

ORCID: 0000-0002-7850-9101

\section{Aneta Sokół}

University of Szczecin

e-mail: aneta.dorota@wp.pl

ORCID: 0000-0002-4675-2182

\section{THE CLIMATE CONDUCIVE TO CREATIVITY IN THE CITY AND ITS IMPACT ON THE DEVELOPMENT OF CREATIVE SECTORS}

\begin{abstract}
Nowadays, creativity has become one of the most important determinants of the development of modern economy. In it lies the potential for economic success not only of entire regions, but above all of business entities. Although creativity is difficult to define, it more frequently becomes the subject of scholarly considerations. In this study, an attempt was made to explore the climate for creativity because it determines the development of creativity and creative attitudes in creative sectors. The main research goal was to show the importance and pattern of the determinants creating a climate conducive to creativity and its impact on the development of creative industries. The method of the study was a critical analysis of the source literature and the author's own research. The aim of the work became the basis for formulating the following research hypothesis: recognising the components constituting a pattern of the climate conducive to creativity in the city will enable better development of entities included in the creative sector. In order to achieve the set goal and verify the research hypothesis, quantitative and qualitative research was carried out among representatives of creative professions employed in the creative sectors. Keywords: creativity, creative sector, climate to creativity, city, development, creative development.
\end{abstract}

\section{Introduction}

In the source literature, researchers involved in analysing creativity recognise a place as the causative factor of a creative character. It has been proven that no creative activity happens in a vacuum because it is a much more socially sensitive phenomenon than others. It is a fact that elements 
of social approval play a significant role in its reception and evaluation. Research on supra-individual creativity is carried out using questionnaires for this purpose as well as observation.

Conditions of the place, as a source of creativity, can be considered with regard to: family context, work context - the organisation as space - the context of the area in which people reside (live). In recent years, representatives of the presented scientific trend have been intensively involved in the environmental conditioning of creativity (for example: Florida, 2002; Landry, 2008; Howkins, 2001). Some of them meet with criticism and rejection of certain assumptions, some recognise that they are interesting and significant research that broadens the understanding of the presented knowledge. In connection with the above, this article is only devoted to the issues of the city space, as a territorial area of residence or temporary stay. The macrosocial level of the space in which creative processes take place is conditioned by the following factors: standard of living, social, religious, ethnic, economic and political factors. It manifests itself in conditions supporting creative people for their individual self-realisation, but also in the whole of society. This dependence interacts in an interactive way, creating feedback within which not only the public encourages creativity, but creative people help in achieving the well-being of society. Florida and Tinagli (2004) think that creativity is one of the main drivers of economic growth. Hence, the place where creative processes take place is extremely important.

Bearing in mind the above, to show a certain scientific area regarding the conditions that create the climate of the city for the development of creativity and creative sectors and subject it to analysis, two trends are distinguished in the article. The first is of a cognitive character focused on analysis of the source literature. These studies included foreign and Polish literature, which made it possible to carry out a critical analysis and to shape the research framework. They concerned issues related to climate concepts for creativity in the city and to climate determinants. The second trend focuses on conducted surveys in the form of a questionnaire and on focus studies on the diagnosis of the climate conducive to creativity, and in the perspective of the development of creative sectors in cities in Poland recognised as the locomotives of creativity i.e. Wrocław, Poznań, Warsaw, Kraków, Katowice. Bearing in mind the purpose of the research for comparison, the study was conducted independently in the city of Szczecin, which is a city that is not considered to be among the top creative cities in which the creative sector is developing intensively. The article assumes that selected climate factors that foster creativity in the city, cer- 
tainly creating its pattern, determine the development of the creative sector. The research was conducted on a group of entities operating in the space of the creative sector. The respondents taking part in the interview work in Szczecin.

\section{Creativity and its significance for the development of creative sectors in the city}

Creativity is a mental process, the ability to create new solutions, that are unusual, original and effective (Torrance, 1966, 1988; Guilford, 1967; Guilford et al., 1978; Ruscio et al., 1998; Runco, 2004; Chavez-Eakle et al., 2007; Gibson et al., 2009; Storm et al., 2011). Creativity requires the use of imagination. Creativity to some extent remains elusive, but its immaterial influence on the value of work results and development in the creative sector is undeniable. It should be noted that as a resource, it generates value for the entity, and thus for the space in which it develops, when conditions for its effective application are created. Skillful generation in entities from the creative sector results in their development and an increase in employees' satisfaction because it encourages intellectual development. However, innovation is the most tangible benefit of creativity for both the entity and the city.

Creativity generates more opportunities for development (Ford, Gioia, 2000; Shin, et. al, 2012). When treating creativity in this way, it should be taken into account that it becomes a means to survive, but it is also an indispensable factor enabling innovative development.

Creativity as a source is distinguished by the following features:

- multidimensional and multifaceted nature, because it concerns various spheres of human life - work, personal life, and leisure time;

- it is valuable because properly used and developed it constitutes an added value;

- it is difficult to follow;

- it is inexhaustible, because it lies in the infinite number of possible creative processes taking place in a given time and space;

- there is no substitute, as it is difficult to find creative entities with the same level of ability;

- it requires the ability to synthesise and the ability to select facts, information and knowledge;

- it is a universal good;

- it is elusive and its measurement is quite difficult; 
- it is dynamic, i.e. capturing only a small part of it can lead to its large increase, and it also has the ability to grow during its use;

- to a large extent it is in the minds of people and it is down to them to disclose it and make it accessible;

- it is independent of such factors as: gender, origin, race;

- its resources are unstable and can be modified at any time;

- it shows features of non-linearity - a lack of clear correlation between the size of creativity and the resulting benefits;

- as a feature it belongs to a concrete individual that owns it, therefore it cannot be bought;

- it can materialise, that is, manifest in products and services, which means it can be imitated;

- its increase occurs when it is positively correlated with the sense of human freedom;

- it is focused on discovering new hitherto unknown areas, it is focused on challenges that can be a source of inspiration and not a problem;

- it is interdisciplinary and causes various synergistic effects at various levels of application.

Creativity plays a special role in the development of creative enterprises included in the creative sector. The creative enterprise in this article should be understood as an entity whose basis for systemic action is the use of tangible and intangible resources in order to effectively use individual mental activities towards merging them into collective processes, striving to achieve a high-level creative process at different levels of organisation and management. The most important resource conditioning the creative process in an enterprise having the right potential of intellectual capital. The pursuit of such an enterprise is dynamic achievement of the growth of value, as well as competitiveness, taking into account the achievement of economic, social and cultural objectives as well as prestigious goals. The productive factor of this type of entity are ideas, products or creative services protected by copyright. In summary, a creative company is a system in which dynamic abilities are used in order to develop creative processes that will generate added value not only for itself, but also for the local environment (Sokół, 2015).

On the other hand, the term creative sectors - in a very general sense - is created by those types of activities in which a significant part of value added arises from the use of intangible assets, and symbolic values of products often are as equally important as their utility value (Stryjakiewicz, Stachowiak, 2010). In such assumptions, entities belonging to this sector are enterprises that use the artistic/creative abilities of their employees or 
The climate conducive to creativity in the city and its impact...

Table 1

Criteria for the division of creative sector enterprises

\begin{tabular}{|l|l|l|l|l|}
\hline \multicolumn{1}{|c|}{$\begin{array}{c}\text { Category of } \\
\text { activity }\end{array}$} & \multicolumn{1}{|c|}{$\begin{array}{c}\text { Creative } \\
\text { activities }\end{array}$} & $\begin{array}{l}\text { Activities related } \\
\text { to copyright }\end{array}$ & $\begin{array}{r}\text { Cultural } \\
\text { activities }\end{array}$ & $\begin{array}{l}\text { Activities related } \\
\text { to digital } \\
\text { processing }\end{array}$ \\
\hline $\begin{array}{l}\text { Type of } \\
\text { activities }\end{array}$ & $\begin{array}{l}\text { advertising } \\
\text { architecture } \\
\text { design } \\
\text { computer soft- } \\
\text { ware, } \\
\text { electronic games } \\
\text { film and TV } \\
\text { music } \\
\text { publishing } \\
\text { fine arts }\end{array}$ & $\begin{array}{l}\text { commercial art } \\
\text { film and video } \\
\text { musical works } \\
\text { publishing } \\
\text { phonography } \\
\text { software } \\
\text { and processing } \\
\text { systems data }\end{array}$ & $\begin{array}{l}\text { museums and } \\
\text { galleries } \\
\text { fine arts } \\
\text { artistic crafts } \\
\text { artistic educa- } \\
\text { tion } \\
\text { radio and televi- } \\
\text { sion } \\
\text { cinematography } \\
\text { libraries }\end{array}$ & $\begin{array}{l}\text { film and video } \\
\text { photography } \\
\text { electronic games } \\
\text { phonography } \\
\text { processing } \\
\text { and storage of } \\
\text { information }\end{array}$ \\
\hline
\end{tabular}

Source: on the basis on: (Hartley, 2004).

entities cooperating with them to make a profit. A common feature of all definitions of the creative sector is that these represent areas of the economy based on the ingenuity and originality of activities using intellectual resources.

The divisions and classifications of the creative sector presented in the world differ from each other. Individual countries, or groups of countries, adopt slightly different criteria for classification of this sector. Often these divisions result from political conditions rather than economic decisions. Such situations were shown by Howkins (2001), who pointed to an important problem that concerned defining and classifying creative sectors in Great Britain and Australia (in the first edition of his book on the creative economy). The problem in question was that a list of creative industries was produced on which only arts and cultural industries were placed, and the area of science and industry in the field of research and patents was excluded.

In connection with the above, referring to the discussion conducted by Howkins, it seems reasonable that while defining the creative sectors, activities related to the intellectual property area should also be included. The area which is expressed in four specific legal forms and other norms also regulating intellectual property rights. These are: copyright law, patent law, trademarks and design marks. With this view in mind, four industries were defined, including the copyright industry (Copyright Industries), the patent industry, trademarks (Trademark Industries) and design branches (Design Industries). The copyright industry includes advertising industry, 
computer programs, design, photography, film, video, theatre productions, music industry, publishing industry, radio, television and video games, art and architecture. The patents department includes industries that manufacture or deal with patents, e.g. the pharmaceutical industry, information and communication technologies, industrial design, chemicals, industry, automotive and other industries. The research and development activity provided by both institutions - commercial and scientific - is dominant - The trade mark industry and the design industry cover a very wide range, within which it is difficult to distinguish copyright from patent industries; and they frequently overlap

\section{Determinants of climate for creativity in the city and the perspective of development of creative sectors}

The climate for creativity in the city is conditioned by the occurrence of factors that influence the degree of creativity of entities participating in the creative sector. To be able to identify the factors that determine that climate, in this article the analysis of available research in the field of creativity and its relationships with the determinants of the environment is used. At the same time, it should be noted that creativity is the basic resource due to which creative sectors can develop. Hence, in the further part of the study, when analysing determinants affecting creativity, it was recognised that they directly affect the development of creative sectors.

The analysis of the source literature allowed indicating as the first of the factors and one of the most important, defined as the sense of gaining an award for creativity. Creativity cannot develop if there is no proper system to encourage the individual to creative effort. Different forms of reward, e.g. public support, a sense of social good, a sense of being honoured and accepted for this form of contribution can become stimulants (Lepper, et. al, 1973; Deci, Ryan, 1985; Gagne, Deci, 2005; Klotz, et al, 2011). Obtaining a reward is related to internal and external motivation, but it should not become a target in itself, because that can cause bad relationships in the community and bring about its disintegration (Luecke, 2003).

It is worth noting here that the climate for creativity, which is characterised by the positive attitude of the community in the city towards creativity, at the same time it eliminates fears among community members of negative assessments and criticisms, which can significantly inhibit their potential and willingness to share ideas with others in the group (Liao, et al, 2007; Bao, et al, 2016; Lee, 2018). It is related to the psychological aspect in the sphere of feelings in the field of security (Edmondson, 
1999, West, 2003). When community members feel they can take risks, they are more likely to present creative ideas. Security is also associated with a sense of trust. At this point it is worth emphasising that many researchers have tried to explain this concept in the context of the development of creativity (Seligman, 1997), trying to distinguish between trust and acquaintance (Luhmann, 1988) confidence (Giddens, 1990, Seligman, 1997), faith (Seligman, 1997) and show the relationship between it and the horizontal creativity in the group. It turned out that trust is not only a psychological phenomenon like the others mentioned above - it is also a social and cultural phenomenon, essentially determining creativity (Bidault, Castello, 2009; Boies, et al., 2015; Yu, et al., 2018).

Another determinant for the development of creativity in the city is an atmosphere conducive to learning and development, including the sharing of knowledge. These behaviours are conditioned by environmental factors and interpersonal relations, e.g. common language, common vision and strength of social interpersonal bonds. This underlines the nature of knowledge flowing through social networks (Brown, Duguid, 2002). Additionally, it is worth stressing that knowledge can also be a valuable source of competitive advantage for business (Bashir, Verma, 2017).

An important determinant conditioning the culture that fosters creativity is proper social support and cooperation. Such support activities should be considered important in four aspects: diversity of community members, mutual openness of thought and ideas, encouraging constructive ideas and shared responsibility for society (Sokół, 2018).

Moreover, cooperation and the level of competition affect the level of culture that promotes creativity, and thus the development of the creative sector. It is difficult to clearly determine what kind of cooperation and competition favours the number of ideas generated. There is no unambiguous compromise here, and both excessive competition, which causes the team's dysfunctions as well as its lack, are negative phenomena. Some studies have shown that competition limits creativity (Amabile, 1982), and others indicated that competition can drive creativity (Clydesdale, 2006; Chen, Chang, 2013; Dustin, et al., 2014).

\section{Diagnosis of the climate conducive to creativity in the city - the authors' own research}

Environmental conditions have a huge impact on the development of creativity, including creative industries in cities. The state of development of creativity and creative sectors in the city is influenced in an indirect or 
direct way by many factors creating a climate conducive to creativity, although not all of them determine the development of these entities to the same extent. Thus, the research element of this article attempts to answer the question which of them stimulate most the development of the creative sector in cities. Obtaining the answer to such a question was not easy, although neither was it impossible, because to estimate which factors affect the development of creativity and creative sectors in cities depended on the locations in which the research was to be conducted. To be able to make a comparative analysis, the cities at the forefront in the rankings for creativity were chosen for the study as representing the most conducive climates for the development of this resource; these were the cities of Wrocław, Poznan, Warsaw, Kraków and Katowice, plus one city that does not belong in this group, namely Szczecin. Thus, it was possible to show differences by creating a model of the components of a climate conducive to creativity in selected Polish cities recognised as those that support the development of this resource and to indicate the level of deviations in the cities that do not belong to this top group. Therefore, when conducting the research process, an effort was made to show which determinants were considered by the respondents as the most important and which were considered to be of lesser importance. This created opportunities to formulate recommendations for decision-makers as to which economic and social areas should be strengthened in order to achieve a higher added value in the form of more effective development of the cities as incubators of creativity and creative sectors.

\subsection{Material and methods}

The article presents the scope of the problems of the author's own research. The research area of the presented topics includes becoming familiar with the issues discussed both at the theoretical level (literature studies on the impact of a climate conducive to creativity in the city in the perspective of the development of creative sectors) and empirical level (by way of surveys and focus group interviews).

In the survey, closed questions were used in relation to the threads associated with a climate conducive to creativity and which conditions the development of the creative sector in the city. The qualitative research focused on group interviews, commonly referred to as focus (FGI).

The research process was divided into three stages. The first stage was conducted in a study group consisting of 241 subjects. These subjects were representatives of creative professions who worked in creative sectors employed in the five cities above referenced recognised as being the most supportive towards creativity. The research was conducted between April and 
December 2017, inclusive. The second stage was carried out in 2019 in order to make a comparative analysis and show how people working in the creative sectors assess climate conditions in the city of Szczecin in relation to creativity. Here, the study group consisted of 96 subjects. The area of empirical research included becoming familiar with all the respondents' opinions on the climate conducive to creativity in the above mentioned cities. To be able to recognise the opinions of people specifically representing creative life orientations (that is, those who, by having creative orientation potential, can contribute much more to the development of creativity than the remainder), the respondents were divided into two groups: one represented those with a creative life orientation and the other, those with a conservative life orientation. This division was accomplished using the life orientation questionnaire in the research process proposed by Cudowska (2014). In the recognition of the preferences for the creative life orientations, the standardised written interview and the scaling method as the way of gathering empirical material, typical of qualitative studies, were applied. The questionnaire consisted of 48 questions and allowed diagnosing creative - CrLO and conservative life orientations - CoLO (version test $\mathrm{Y}, \mathrm{N}, \mathrm{NK}$ or A, a, b, B). The questions related to 8 key considerations (components) directly related to creativity and the development of a local climate capable of promoting and supporting a creative sector in cities (Table 2). The three areas of the studies were distinguished as: innovation, originality and value. These listed values regardless of the accepted concepts of creativity, theoretical inspiration or methodological depictions, were repeated in all characteristics of the phenomenon, both in static and dynamic terms. Cudowska (2014) shows that the questionnaire affords a high degree of reliability as a research tool. The characteristics of the subjects taking into account the results of research in the field of life orientation are presented in Table 2 below. The third and final stage of the study, included focus studies. These were carried out in June 2019 to add depth to the research results obtained. The research was conducted in a group of 9 subjects (all working students) who demonstrated creative life orientation. The aim of the focus study was to deepen the results of the quantitative research and to provide justification as to which determinants most affect the development of creative industries.

A common feature of the research processes was their cyclicality and interdependence. In the research, different criteria for their division were used. In terms of time criterion, historical (ex post), current and prospective (ex ante) studies were used. The aim was to assess the existing economic phenomena as well as forecasting. The research also aimed to provide needed information in the area of establishing the pattern of a climate conducive 
to creativity and its impact on the development of the creative sector in the city. Taking into account the purpose of the research, exploratory, descriptive and cause-and-effect research was applied.

Table 2

Creative study, life orientations - working in creative sector

\begin{tabular}{|c|c|c|c|c|c|}
\hline \multicolumn{6}{|c|}{$\begin{array}{l}\text { Working in the creative sector }-\mathbf{2 1 4} \text { subjects } \\
\text { Wrocław, Poznań, Warszawa, Kraków, Katowice }\end{array}$} \\
\hline \multicolumn{3}{|c|}{ Test $(\mathrm{Y}, \mathrm{N}, \mathrm{NK})$} & \multicolumn{3}{|c|}{ Test $(\mathrm{A}, \mathrm{a}, \mathrm{b}, \mathrm{B})$} \\
\hline \multicolumn{3}{|c|}{ CrLO - CoLO } & \multicolumn{3}{|c|}{ CrLO - CoLO } \\
\hline relation & subjects & $\%$ & relation & subjects & $\%$ \\
\hline$>=0 *$ & 63 & $29.44 \%$ & $>=0$ & 80 & $37.38 \%$ \\
\hline$<0^{*}$ & 151 & $70.56 \%$ & $<0$ & 134 & $62.62 \%$ \\
\hline \multicolumn{6}{|c|}{$\begin{array}{c}\text { Working in the creative sector }-96 \text { persons } \\
\text { Szczecin }\end{array}$} \\
\hline \multicolumn{3}{|c|}{ Test $(\mathrm{Y}, \mathrm{N}, \mathrm{NK})$} & \multicolumn{3}{|c|}{ Test $(\mathrm{A}, \mathrm{a}, \mathrm{b}, \mathrm{B})$} \\
\hline \multicolumn{3}{|c|}{ CrLO - CoLO } & \multicolumn{3}{|c|}{ CrLO - CoLO } \\
\hline relation & subjects & $\%$ & relation & subjects & $\%$ \\
\hline$>=0^{*}$ & 28 & $29,16 \%$ & $>=0^{*}$ & 31 & $32,29 \%$ \\
\hline$<0^{*}$ & 68 & $70,83 \%$ & $<0^{*}$ & 65 & $67,71 \%$ \\
\hline
\end{tabular}

Value of difference greater or equal to zero $(>=0)$ denotes a CrLO value. Value of difference less than zero $(<0)$ denotes a CoLO value*

Source: authors' own research.

In connection with the above, the following hypothesis has been put forward: Recognition of the components constituting the pattern of a climate conducive to creativity in the city will enable better development of entities included in the creative sector.

\subsection{Results of quantitative research}

The research presented in this part of the article is to show what components are included in the design of a climate conducive to creativity in the city and which of them determine the development of creative sectors. The decision as to how to conceptualise the climate conducive to in the city in the form of choosing determinants was conditioned by the context of the study and referred to the verification of the research presented in the article shown in item 3 of the article. 
In order to be able to better define the specificity of the functioning of creative sector entities in the context of the components needed to create a suitable climate conducive to creativity in the city, a comparative analysis has been made within the range of distinguishing entities located in the cities of Wrocław, Poznań, Warsaw, Kraków and Katowice, and in contrast, the city of Szczecin. Thus, as a result of the analysis of collected data, it can be ascertained that in the study group of 214 subjects the most important factors conditioning the development of creativity and creative industries in the city (by number of respondents selecting the factor) were: atmosphere for learning and development [5] - 178 (83.18\% of respondents); social support [7] -176 (82.24\% of respondents); sense of security [6] -156 (72.90\% of respondents); atmosphere for sharing knowledge [4] - 145 (67.76\% of respondents). Factors deemed to be of lesser significance by the study group, were: reward recognition [1] - 109 (50.93\% of respondents); social cooperation [8] - 87 (40.65\% of respondents); reward authority [2] 78 (36.45\% of respondents). By contrast, in the study group of 96 subjects the most important factors for them were: the atmosphere for sharing knowledge [4] - 43 (44.79\% of respondents); reward recognition [1] - 38 (39.58\% of respondents); sense of security [6] -34 (35.42\% of respondents); reward celebration [3] -29 (30.21\% of respondents); social support [7] -28 (29.17\% of respondents). Factors deemed to be of lesser significance by this group were: reward authority [2] - 12 (12.50\% of respondents); social cooperation [8] - 19 (19.79\% of respondents).

Table 3

Which factors, in your opinion, determine the climate conducive to the sector creative?

\begin{tabular}{|c|c|c|c|c|c|c|c|c|c|}
\hline \multirow{2}{*}{ Answer } & \multicolumn{3}{|c|}{214 subjects } & \multicolumn{5}{c|}{96 subjects } \\
\cline { 2 - 10 } & \multicolumn{2}{|c|}{ Total } & \multicolumn{2}{c|}{$\begin{array}{c}\text { CrLO } \\
\text { subjects }\end{array}$} & \multicolumn{2}{c|}{ Total } & \multicolumn{2}{c|}{$\begin{array}{c}\text { CrLO } \\
\text { subjects }\end{array}$} \\
\cline { 2 - 10 } & Number & $\%$ & Number & $\%$ & Number & $\%$ & Number & $\%$ \\
\hline (A) I agree (B) I don't agree (C) I don't know \\
\hline [1] Reward - recognition \\
\hline (A) & 109 & 50,93 & 28 & 44,44 & 38 & 39,58 & 15 & 28,57 \\
\hline (B) & 74 & 34,58 & 32 & 50,79 & 24 & 25,00 & 8 & 25,81 \\
\hline (C) & 31 & 14,49 & 3 & 4,76 & 34 & 35,42 & 8 & 25,81 \\
\hline [2] Reward - authority & 78 & 36,45 & 20 & 31,75 & 12 & 12,50 & 19 & 61,29 \\
\hline (A) & 78 & 10,75 & 15 & 23,81 & 34 & 35,42 & 4 & 12,90 \\
\hline (B) & 23 & 52,80 & 28 & 44,44 & 50 & 52,08 & 8 & 25,81 \\
\hline (C) & 113 & 52 & & & & \\
\hline
\end{tabular}




\begin{tabular}{|c|c|c|c|c|c|c|c|c|}
\hline \multirow{3}{*}{ Answer } & \multicolumn{4}{|c|}{214 subjects } & \multicolumn{4}{|c|}{96 subjects } \\
\hline & \multicolumn{2}{|c|}{ Total } & \multicolumn{2}{|c|}{$\begin{array}{c}\text { CrLO } \\
63 \text { subjects }\end{array}$} & \multicolumn{2}{|c|}{ Total } & \multicolumn{2}{|c|}{$\begin{array}{c}\text { CrLO } \\
31 \text { subjects }\end{array}$} \\
\hline & Number & $\%$ & Number & $\%$ & Number & $\%$ & Number & $\%$ \\
\hline \multicolumn{9}{|c|}{ (A) I agree (B) I don't agree (C) I don't know } \\
\hline \multicolumn{9}{|c|}{ [3] Reward - celebration } \\
\hline$(\mathrm{A})$ & 34 & 15,89 & 18 & 28,57 & 29 & 30,21 & 3 & 9,68 \\
\hline (B) & 32 & 14,95 & 14 & 22,22 & 34 & 35,42 & 21 & 67,74 \\
\hline (C) & 148 & 69,16 & 31 & 49,21 & 33 & 34,38 & 7 & 22,58 \\
\hline \multicolumn{9}{|c|}{ [4] Atmosphere - sharing knowledge } \\
\hline (A) & 145 & 67,76 & 44 & 69,84 & 43 & 44,79 & 12 & 38,71 \\
\hline (B) & 56 & 26,17 & 11 & 17,46 & 26 & 27,08 & 11 & 35,48 \\
\hline (C) & 13 & 6,07 & 8 & 12,70 & 27 & 28,13 & 8 & 25,81 \\
\hline \multicolumn{9}{|c|}{ [5] Atmosphere - learning and development } \\
\hline$(\mathrm{A})$ & 178 & 83,18 & 51 & 80,95 & 23 & 23,96 & 8 & 25,81 \\
\hline (B) & 29 & 13,55 & 4 & 6,35 & 39 & 40,63 & 17 & 54,84 \\
\hline$(\mathrm{C})$ & 7 & 3,27 & 8 & 12,70 & 34 & 35,42 & 6 & 19,35 \\
\hline \multicolumn{9}{|c|}{ [6] Sense of security } \\
\hline$(\mathrm{A})$ & 156 & 72,90 & 39 & 61,90 & 34 & 35,42 & 15 & 48,39 \\
\hline (B) & 15 & 7,01 & 18 & 28,57 & 17 & 17,71 & 7 & 22,58 \\
\hline$(\mathrm{C})$ & 43 & 20,09 & 6 & 9,52 & 45 & 46,88 & 9 & 29,03 \\
\hline \multicolumn{9}{|c|}{ [7] Social support } \\
\hline$(\mathrm{A})$ & 176 & 82,24 & 42 & 69,84 & 28 & 29,17 & 9 & 29,03 \\
\hline (B) & 36 & 16,82 & 15 & 23,81 & 25 & 26,04 & 15 & 48,39 \\
\hline (C) & '2 & 0,93 & 6 & 9,52 & 43 & 44,79 & 7 & 22,58 \\
\hline \multicolumn{9}{|c|}{ [8] Social cooperation } \\
\hline$(\mathrm{A})$ & 87 & 40,65 & 29 & 46,03 & 19 & 19,79 & 21 & 28,57 \\
\hline (B) & 65 & 30,37 & 23 & 36,51 & 30 & 31,25 & 3 & 9,68 \\
\hline (C) & 62 & 28,97 & 11 & 17,46 & 47 & 48,96 & 7 & 22,58 \\
\hline
\end{tabular}

Source: authors' own research.

In presenting research results in relation to subjects who themselves represent creative life orientations (63 subjects) in the group of 214 subjects, it should be noted that for this particular study group the most important factors for them in conditioning the development of creativity and creative sectors were: atmosphere for learning and development [5] - 51 (80.95\% of respondents); atmosphere for sharing knowledge [4] - this $44(69.84 \%$ of respondents); social support [7] - 42 (66.67\% of respondents); sense of 
security [6] - 39 (61,90\% of respondents); reward recognition [1] - 28 people (44.44\% of respondents). Factors deemed to be of lesser significance by this group were: reward celebration [3] - 18 (28.57\% of respondents).

In relation to similarly creative life orientated subjects (31 subjects) drawn from the group of 96 subjects in Szczecin, the most important factors for them in conditioning the development of creativity and creative sectors were: social support [7] - 21 ( $67.74 \%$ of respondents); reward recognition [1] - 15 (48.39\% of respondents); sense of security [6] - 15 (48.39\% of respondents). Factors deemed to be of lesser significance in this group were: reward celebration [3] -3 (9.68\% of respondents); atmosphere for learning and development [5] -8 (25.81\% of respondents); social support [7] -9 (29.03\% of respondents).

\subsection{Results of focus group research}

In the qualitative study, focused group interviews, commonly referred to as focus (FGI), were conducted. Discussion took place within which the phenomena related to becoming familiar with detailed opinion on the research components, their contribution to providing a climate conducive to creativity, and their influence on the processes of promoting creativity and developing a creative sector were analysed. The participants involved in the discussion were employed in the following industries: advertising, promotion and IT. In the first instance, the participants were asked about the role of creativity as a value added generator in the aspect of obtaining economic benefits in the city and its impact on the development of creative sectors. In the survey group, this role was defined primarily as the source of any innovation due to which progress and development take place. One of the participants defined the role of creativity as a source of undeniable development. Another believed that in their opinion creativity makes the world more interesting because such development creates new opportunities, while others indicated that creativity plays the role of a trigger for any development, including creative industries. Taking into account the purpose of the research, the participants were presented with the results of quantitative research (cf. section 4.2) obtained in two research cycles. They were asked to justify the choices made by the respondents and whether they agreed with the results presented.

Among the answers provided, the participants were aware (given the answers obtained in the questionnaires from both groups, both generally and in the responses of creative life orientated subjects that formed sub-groups) that social support is by far the most important factor for the development of creativity in the community and for developing creative sectors. The jus- 
tification for this statement was that: when the group shows tolerance and support then automatically (according to one of the participants) a sense of security arises and this creates a space to acquire knowledge and share it and a desire to use it to create new ideas. One participant suggested that a sense of security in society triggers all other processes mentioned and that in itself is an important development factor. Bearing in mind this statement, the participants were then asked which of the determinants of the climate for creativity is, according to them, more important for the development of creativity and creative sectors and whether social support has an advantage over the sense of security or vice versa. The participants agreed concordantly that in their opinion social support gives a sense of security and that it is this which is the key to the development of creativity and creative industries, including the creation of a proper climate for creativity.

The participants were asked whether: they agree that reward recognition, reward authority and social cooperation are factors that have a much smaller impact on a climate that properly favours creativity and thus on creativity of the community and the development of creative industries in the subject cities. In this regard, the participants were not concordant in their answers. Namely, they acknowledged that the sense of being rewarded always motivates people and not only for creative abilities. However, no reward will be conducive to the development of creativity if there is no social support, acceptance or sense of security. Therefore, the respondents stated that reward could be considered as a less significant determinant. As far as social cooperation is concerned, the participants decided that it is definitely more important than reward because through cooperation the group develops support, a sense of security and the atmosphere of sharing knowledge. Thus, the respondents were asked whether support can be considered as a subordinate factor, or whether it should be classified in the first group, i.e. as a determinant of key importance in creating a proper climate conducive to creativity. Most of the participants indicated that social cooperation is also crucial for a climate conducive to creativity in the city. Good cooperation, according to one of the participants, shapes the right social relations and creates space for development.

The last issue was to become familiar with the opinion of whether Szczecin stands out in the context of other cities studied in relation to the climate for creativity and what it is that characterises the discussion of the participants. The participants acknowledged that in Szczecin, in their opinion, creativity could develop better. Again, in their opinion, the cities of Warsaw, Wrocław or Poznań definitely provide a better atmosphere for creativity than Szczecin. In connection with this, the respondents were then 
The climate conducive to creativity in the city and its impact...

asked what is such a distinguishing feature that makes these cities lead and outrun Szczecin in creating a climate for creativity. The respondents believed that environmental conditions in the form of the promotion of cities and encouraging initiatives caused that in those cities the climate for creativity was better. When asked to indicate specific solutions, the respondents had a problem with their indication. One respondent replied that the mentality instilled in recent years, that these cities are the leaders in economic development compared to other Polish cities and that they foster the development of creativity, makes us think so. However, another participant pointed out that cultural initiatives and the promotion of culture are of special importance in the development of creativity, and there are far fewer intitiatives in Szczecin than in the cities mentioned.

Finally, the respondents were asked which of the listed components in their opinion determines the development of creativity and creative sectors (the respondents were required to take into account the level of importance of the two most significant components, i.e. those that determine most). According to the vast majority, they were: atmosphere for learning and sense of security.

\section{Conclusions}

In the source literature, analyses of the climate conducive to creativity in the city inspire researchers to recognise further scientific areas and contribute to the development of this issue. Unfortunately, this concept is poorly recognised on both theoretical and empirical grounds. In the source literature, if available, the analyses carried out relate to quantitative as well as qualitative research. Although the latter is rare, its application may make the knowledge contained therein deepen the empiria obtained from analytical studies. This was also done in this study, in which, in addition to quantitative research, focused group interviews were used. The conclusions obtained in the study indicate that the appropriate pattern of climate for creativity, according to the authors, has an impact on the development of the creative sector. For the most part, the data gathered in our research, illustrates the many years of similar research carried out by various other authors on the factors involved in creating a climate conducive to promoting, developing and supporting creativity, that has enabled a positive verification of the hypothesis set in this article.

Thus on the basis of the results obtained from our research, it can be said that the pattern of a creative climate in cities, recognised as conducive to creativity, contains the following components: an atmosphere for learn- 
ing and development, social support, a sense of security and an atmosphere for acquiring knowledge. However, in a city that does not meet the same criteria, the climate pattern changes to consist of the following features: an atmosphere for acquiring knowledge, reward recognition, a sense of security, reward celebration and social support. For those who fall into the category of being creative life orientated from cities recognised as less conducive to creativity, the creative climate pattern includes: an atmosphere for learning and development, an atmosphere for acquiring knowledge, social support, a sense of security and reward recognition. Whereas, for those from a city that is not designated as being creative, the pattern is: social support, reward recognition and a sense of security.

In connection with the above an important determinant that favours creativity in the context of elements that produce a climate conducive to its promotion, is the adequate support of social groups, which was seen by the respondents as important. While referring to this component, it is worth mentioning that such support is in fact important in four aspects: diversity, mutual openness of thought and ideas, the encouragement of constructive ideas and shared responsibility (Amabile, 1988; Amabile et al., 1996 acc. to: Franková, 2011). It was similarly observed that positive attitude and support affect the sense of security. The research results also appear to confirm the thesis presented in the source literature that the university atmosphere of knowledge sharing, as one of the most important elements of climate creativity, plays an equally important role in the development of creativity in business entities and cities.

Social cooperation and its resulting synergy affect the level of creativity development and entities included in the creative sector. However, it is difficult to clearly determine what kind of cooperation is conducive to the number and variety of ideas generated.

Bearing in mind the development of a proper climate for creativity in the city, local authorities should pay special attention to the aspects mentioned above, because they are important components that conditions the development of potential for innovation. Care in fostering these key aspects will also lead to improvements in the life of the inhabitants of a given territorial area. Bearing in mind the development of the creative sector in the context of the indicated patterns of the climate conducive to creativity, decision-makers should take specific actions in the field of its development:

- creation of the function of ambassadors of creativity;

- supporting the development of infrastructure/tools that allow the development of creative entities; 
- facilitating access to external financing sources for research and development as well as to private and public creativity;

- supporting the development of the information society;

- orientation of the research and scientific community and entrepreneurs towards development purposes;

- promoting cooperation between the world of scientists and entities developing creativity other than universities;

- activation of cooperation between central and regional government levels in the scope of shaping and implementing educational policy focused on the development of creative entities;

- creation of a proper information exchange system;

- creating an appropriate system for measuring and monitoring changes in the area of networking and information exchange.

- promoting and stimulating creative attitudes in society by involving people who are known and liked in propagating the above ideas;

- effective use of creative potential inherent in local society and promoting its development;

- tolerance for diversity and otherness;

- freedom to express oneself.

- reducing the stereotypes of thinking and perception of others and their otherness;

- environment orientation (change of the mental model) towards the needs of the economy;

- dissemination of modern communication methods and popularisation of creative content;

- transformations in the field of social awareness - elimination of stereotypes, illusions and prejudices in order to build a society open to changes;

- creating a new city culture aimed at effective creative development, especially in the defined enclaves of poverty.

\section{Funding}

The project is financed under the program of the Minister of Science and Higher Education under the name "Regional Initiative of Excellence" in 2019-2022 project number 001/RID/2018/19 financing amount $10,684,000.00 "$

\section{Author contributions}

Sylwia Pangsy-Kania and Aneta Sokół conceived the study and were responsible for the design and development of the data analysis. They were also responsible for data collection, analysis and interpretation. 


\section{Disclosure statement}

We declare that we do not have any competing financial, professional, or personal interests from other parties.

\section{R E F E R E N C E S}

Amabile, T.M. (1988). A model of creativity and innovation in organizations. [in:] B. M. Staw, L. L. Cummings (ed.), Research in organizational behavior 10: $123-167$.

Amabile, T.M. (1996). Creativity in Context: Update to the Social Psychology of Creativity. Westview Press: Boulder.

Bao, G. M., Xu, B. X., \& Zhang, Z. Y. (2016). Employees' trust and their knowledge sharing and integration: The mediating roles of organizational identification and organization based self-esteem. Knowledge Management Research E3 Practice 14(3): 362-375. https://doi.org/10.1057/kmrp.2015.1

Bashir, M., Verma, R. (2017). Why Business Model Innovation. Is the New Competitive Advantage. The IUP Journal of Business Strategy 15(1). https:// www.researchgate.net/publication/316644311_WhyBusiness_Model_Innovat ion_is_the_New_Competitive_Advantage

Bidault, F., Castello, A. (2009). Trust and creativity: understanding the role of trust in creativity-oriented joint developments. RE์D Management 39(3): 259-270. https://doi.org/10.1111/j.1467-9310.2009.00557.x

Boies, K., Fiset, J., Gill, H. (2015). Communication and trust are key: unlocking the relationship between leadership and team performance and creativity. The Leadership Quarterly 26(6), 1080-1094. https://doi.org/10.1016/j.leaqua. 2015.07.007

Brown, J.S. Duguid, P. (2002). The Social Life of Information. Cambridge: Harvard Business School Press.

Deci, E. L., Ryan, R. M. (1985). Intrinsic motivation and self-determination in human behavior. New York: Plenum.

Dustin, G., Bharat, M., Jitendra, M. (2014). Competitive Advantage and Motivating Innovation. Advant in Management 7 (1): 1-8.

Edmondson AC. 1999. Psychological safety and learning behavior in work teams. Administrative Sciences 44(2): 350-83. https://doi.org/10.2307/2666999

Chavez-Eakle R. A., Graff-Guerrero A., García-Reyna J. C., Vaugier V., CruzFuentes C. (2007). Cerebral blood flow associated with creative performance: a comparative study. Neuroimage 38: 519-528. https://doi.org/10.1016/j.neu roimage.2007.07.05

Chen, Y., Chang, C. (2013). The Determinants of Green Product Development Performance: Green Dynamic Capabilities, Green Transformational Leadership and Green Creativity. Journal of Business Ethics 116: 107-19. https://doi.org/10.1007/s10551-012-1452-x 
Clydesdale, G., (2006). Creativity and Competition: The Beatles. Creativity Research Journal, 18(2): 129-139. http://www.informaworld.com/openurl?gen $\mathrm{re}=\operatorname{article\& doi}=10.1207 / \mathrm{s} 15326934 \mathrm{crj} 1802 \_1 \& \mathrm{magic}=$ crossref

Cudowska, A. (2004). Ksztaltowanie twórczych orientacji życiowych $w$ procesie edukacji. [Development of creative live orientations in educational process]. Białystok: Trans Humana.

Florida, R. (2002). The rise of the creative class: And how it is transforming work, leisure, community and everyday life. New York: Basic Books.

Ford, C. M., Gioia, D. A. (2000). Factors influencing creativity in the domain of managerial decision making. Journal of Management 26(4): 705-732. https://doi.org/10.1177/014920630002600406

Franková, E. (2011). Kreativita a inovace v organizaci [Creativity and innovation in the organization]. Praha: Grada.

Gagne', M., Deci, E. L. (2005). Self-determination theory and work motivation. Journal of Organizational Behavior, 26, 331-362. https://doi.org/10.1002/ job. 322

Gibson C., Folley B. S., Park S. (2009). Enhanced divergent thinking and creativity in musicians: a behavioral and near-infrared spectroscopy study. Brain Cogn. 69: 162-169. https://doi.org/10.1016/j.bandc.2008.07.009

Giddens, A. (1990). Consequences of Modernity. Oxford: Polity Press.

Guilford J. P. (1967). The nature of human intelligence. New York: McGraw-Hil.

Guilford J. P., Christensen P. R., Merrifield P. R., Wilson R. C. (1978). Alternate Uses: Manual of Instructions and Interpretations. Orange, CA: Sheridan Psychological Services.

Hartley, J. (2004). Creative Industries. London: Wiley Blackwell.

Howkins, J. (2001). The Creative Economy. How people make money from ideas, The Penguin Press.

Klotz, A. C., Wheeler, A. R., Halbesleben, J., Brock, M. E., Buckley, M. R. (2011). Can reward systems influence the creative individual? [in:] Mumford, M. D. (ed.), Handbook of organizational creativity. Oxford, UK: Elsevier Science.

Landry, Ch. (2008). The Creative City. A Toolkit for Urban Innovators. London: Earthscan.

Lee, J. (2018). The Effects of Knowledge Sharing on Individual Creativity in Higher Education Institutions: Socio-Technical View. Administrative Sciences 8(21). http://dx.doi.org/1010.3390/admsci8020021

Lepper, M. R., Greene, D., Nisbett, R. E. (1973). Undermining children's intrinsic interest with extrinsic reward: A test of the overjustification hypothesis. Journal of personality and social psychology 28: 129-137. http://dx.doi.org/ $10.1037 / \mathrm{h} 0035519$ 
Liao, S. H., Fei, W. C., Chen, C. C. (2007). Knowledge sharing, absorptive capacity, and innovation capability: An empirical study of Taiwan's knowledge intensive industries. Journal of Information Science 33(3): 340-359. https://doi.org/10.1177/0165551506070739

Luecke, R. (2003). Managing creativity and innovation. Boston: Harvard Business School Press.

Luhmann, N. (1988) Familiarity, Confidence, Trust: Problems and Alternatives. [in:] D. Gambetta (ed.), Trust: Making and Breaking Cooperative Relations. Oxford: Basil Blackwell.

Runco, M. A. (2004). Creativity. Annual Review of Psychology 55: 657-687. http://dx.doi.org/10.1146/annurev.psych.55.090902.141502

Seligman, A. (1997). The Problem of Trust. Princeton University Press.

Shin, S. J., Kim, T. Y., Lee, J. Y., Bian, L. (2012). Cognitive team diversity and individual team creativity: A crosslevel interaction. Academy of Management Journal 55(1): 197-212. https://doi.org/10.5465/amj.2010.0270

Sokół, A. (2018). National economic culture and creative life orientations versus creative sectors. Hradec Kralove - Vilinius: Mykolas Romeris University. International Academic Network Human potential development in Central and Eastern EU States, Vilnius. Lithuania Magnimitas.

Sokól, A. (2015). Zarzadzanie twórczościa w organizacji. Koncepcja, metody $i$ narzedzia [Creative management in the organization. Concept, methods and tools]. Warsaw: CeDeWu.

Storm B. C., Angello G., Bjork E. L. (2011). Thinking can cause forgetting: memory dynamics in creative problem solving. J. Exp. Psychol. Learn. Mem. Cogn. 37 1287-1293. https://doi.org/10.1037/a0023921

Stryjakiewicz, T., Stachowiak, K., (2010). Sektor kreatywny w poznańskim obszarze metropolitalnym. Tom 1. Uwarunkowania, poziom $i$ dynamika rozwoju sektora kreatywnego w poznańskim obszarze metropolitalnym [Creative sector in the Poznań metropolitan area. Volume 1. Conditions, level and dynamics of the creative sector development in the Poznań metropolitan area]. Poznan: Bogucki.

Torrance E. P. (1966). Torrance Tests of Creative Thinking. Lexington, KY: Personnel Press.

Torrance E. P. (1988). The nature of creativity as manifest in its testing [in:] R. J. Sternberg (ed.) The Nature of Creativity: Contemporary Psychological Perspectives. New York, NY: Cambridge University Press.

Yu. M. Ch, Mai, Ch., Tsai, S. B., Da, Y. (2018). An Empirical Study on the Organizational Trust, Employee-Organization Relationship and Innovative Behavior from the Integrated Perspective of Social Exchange and Organizational Sustainability. Sustainability 10(3): 864. https://doi.org/10.3390/su10030864

West, M. A. (2003). Innovation implementation in work teams. [in:] P. B. Paulus, B. A. Nijstad (eds.), Group creativity: Innovation through collaboration. New York, NY: Oxford University Press. 